\title{
Erratum
}

Strahlenther Onkol 2014 · 190:321-321

DOI 10.1007/s00066-013-0544-6

Published online: 21. February

(c) Springer-Verlag Berlin Heidelberg 2014

D. Rades ${ }^{1} \cdot$ N.D. Seibold ${ }^{1}$. S.E. Schild ${ }^{2} \cdot$ K.L. Bruchhage ${ }^{3} \cdot$ M.P. Gebhard $^{4} \cdot$ F. Noack ${ }^{4}$

${ }^{1}$ Department of Radiation Oncology, University of Lübeck

${ }^{2}$ Department of Radiation Oncology, Mayo Clinic Scottsdale, Scottsdale

${ }^{3}$ Department of Oto-Rhino-Laryngology and Head and Neck Surgery, University of Lübeck

${ }^{4}$ Institute of Pathology, University of Lübeck

\section{Erratum to: Androgen receptor expression}

\section{Prognostic value in locally advanced squamous cell carcinoma of the head and neck}

Unfortunately, the author K.L.

Bruchhage's name was omitted in the original publication of the article. The missing author's name and the correct order of the authors are provided below:

D. Rades $\cdot$ N.D. Seibold $\cdot$ S.E. Schild . K.L. Bruchhage · M.P. Gebhard · F. Noack

\section{Corresponding address}

\section{Prof. Dr. D. Rades}

Department of Radiation Oncology, University of Lübeck

Ratzeburger Allee 160, 23538 Lübeck

Germany

rades.dirk@gmx.net

The online version of the original article can be found at:

http://dx.doi.org/10.1007/s00066-013-0389-z 